\title{
Ethical Issues in Radioisotope Shortages: Rationing and Priority Setting*
}

\author{
M. Sara Rosenthal ${ }^{1}$

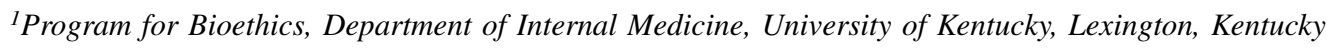

\begin{abstract}
In recent years, shortages of radioisotopes that cannot be stockpiled have created a scenario in which they may be considered, periodically, a scarce medical resource. This discussion focuses on the just allocation of medical radioisotopes and presents the dominant ethical frameworks for rationing and priority setting in the patient populations most affected. Priority setting is necessary when demand for a scarce resource exceeds supply. On completion of this article, the reader will be able to describe the origins of rationing and priority setting in medicine, as well as ethically sound frameworks for rationing. Finally, the process for priority setting and the need for transparency of this process in the nuclear medicine setting are outlined.
\end{abstract}

Key Words: radioisotope shortage; bioethics; priority setting; resource allocation; rationing; scarce resources

J Nucl Med Technol 2010; 38:117-120

DOI: 10.2967/jnmt.110.081117

$\mathbf{T}$ he production of medical isotopes is in crisis and is built on a house of cards; adequate production is dependent on 5 aging nuclear reactors that are being stretched beyond their lifetime operational capacities. In 2008, the president of the Society of Nuclear Medicine stated that the United States and other countries are not prepared to adequately deal with a shortage crisis, nor could they anticipate or prevent additional shortages (1). Since 2007, as reactor shutdowns have occurred, nuclear medicine practitioners throughout North America and Europe, in particular, have needed to ration medical isotopes, cancel or postpone procedures, and pay higher costs for medical isotopes. This has created ethical problems surrounding beneficent care for patients, and rationing decisions are frequently being made by individual practitioners who may not have sufficient

\footnotetext{
Received Jul. 12, 2010; revision accepted Aug. 5, 2010.

For correspondence or reprints contact: M. Sara Rosenthal, Program for Bioethics, Department of Internal Medicine, University of Kentucky, K522-740

S. Limestone St., Lexington, KY 40536-0284.

E-mail: msrose2@email.uky.edu

*NOTE: FOR CE CREDIT, YOU CAN ACCESS THIS ACTIVITY THROUGH THE SNM WEB SITE (http://www.snm.org/ce_online) THROUGH SEPTEMBER 2012.

COPYRIGHT ( 2010 by the Society of Nuclear Medicine, Inc.
}

knowledge or expertise in effective and sound prioritysetting frameworks. This article reviews the background to the medical isotope shortage, illustrates key historical lessons learned from rationing medical care, and proposes sound priority-setting frameworks for nuclear medicine departments to adopt.

\section{BACKGROUND}

The current production of ${ }^{235} \mathrm{U}$ for medical use depends on nuclear reactors that are old and unreliable $(2,3)$. Although the United States is the primary supplier of highly enriched uranium to these reactors and consumes most of the world's supply of the precursor isotope, ${ }^{99} \mathrm{Mo}$, none of the isotopes have been produced in the United States since $1989(2,3)$.

Irradiation of ${ }^{235} \mathrm{U}$ with neutrons produces fission fragments containing ${ }^{99} \mathrm{Mo}$, which has a half-life of $66 \mathrm{~h}$, and radioactive ${ }^{131} \mathrm{I}$, which has a half-life of approximately $8 \mathrm{~d}$, as well as ${ }^{133} \mathrm{Xe}(2,4) .{ }^{99} \mathrm{Mo}$ decays to ${ }^{99 \mathrm{~m}} \mathrm{Tc}$, used for $80 \%-90 \%$ of all nuclear medicine procedures worldwide (2). ${ }^{131} \mathrm{I}$ is used in diagnosis and treatment of thyroid disease and for other malignancies when coupled to antibodies $(2,5)$.

Of the 5 commercial nuclear reactors in operation, all are over 40 y old $(2,4,6)$. North America is serviced mainly by 2 reactors $(1,7,8)$ : The National Research Universal Reactor in Chalk River, Ontario, Canada, and the High Flux Reactor in Petten, The Netherlands. The Canadian reactor was taken off-line in $2009(6,9)$, and the reactor in Petten was taken off-line for long periods in 2008 and 2009 (3).

Three reactors provide medical isotopes for most of Europe, including the reactor in Petten; the BR2 in Mol, Belgium; and the Osiris in Saclay, France. All of these reactors were off-line for long periods in 2008. The Safari 1 reactor, in Pelindaba, South Africa, services other parts of the world but does not have the capacity to make up the shortfall for North America and Europe when other reactors are down (10). The Canadian reactor meets $40 \%$ of the global medical isotope demand and produces $50 \%$ of the medical isotopes used in North America (1). The reactor in Petten provides one third of the global medical isotope needs; the Canadian and Petten facilities supply two thirds of the global supply of ${ }^{99} \mathrm{Mo}$ and ${ }^{131} \mathrm{I}$ (6). When the 
Canadian reactor was shut down sporadically in 2007 and 2008, supplies were significantly affected. However, when both were shut down in 2009 , one due to a leak of contaminated water and the other for maintenance, the situation went from a significant shortage to a critical one. In 2009, the Canadian reactor's shutdown imperiled roughly 8 million planned nuclear studies (9). The situation became so serious in 2009 that the Society for Nuclear Medicine set up an online ${ }^{99}$ Mo Shortage Resource Center. Additionally, nuclear medicine departments were advised to alert clinicians about alternative diagnostic studies during the 2009 shortage (9).

A survey conducted August 2009 by the Society for Nuclear Medicine and the National Association of Nuclear Pharmacies found that $60 \%$ of respondents reported being affected by the 2009 shortage (2).

The Society for Nuclear Medicine issued the following public statement in 2008 (9): "The practice of nuclear medicine across North America is in serious danger. An increasing number of hospitals and imaging centers across the U.S. and Canada are prioritizing their patient lists. . and may be unable to treat patients with cancer, thyroid, heart and kidney disease."

The future of nuclear reactors that supply medical isotopes remains uncertain. The Canadian reactor started operating in $1957(10,11)$ and was initially scheduled to close in 2005, as 2 new reactors were poised to open in the same Chalk River location: the Multipurpose Applied Physics Lattice Experiment reactors 1 and 2 (MAPLE 1 and MAPLE 2). MAPLE 1 was supposed to be operational by 1999 but was declared unsafe by Atomic Energy of Canada Limited (AECL). The MAPLE project was actually shut down in 2008, and there are no new reactors commissioned at this time for Chalk River. AECL appeared before the Canadian Nuclear Safety Commission in a public hearing to consider AECL's application for the restart of the National Research Universal reactor; this application was approved on July 7, 2010 (11-13). The restart, however, is only a temporary fix to a worsening problem.

The Petten reactor, which started operating in 1962 (14), has required shut-downs for repairs. The Nuclear Research and Consultancy Group is in the process of designing the Pallas reactor as the replacement for the Petten reactor, but it is not scheduled for completion until 2016, and this is considered to be an optimistic deadline (10). In France, the Jules Horowitz reactor becomes operational around 2015 and is planned to replace the current reactor, which needs to be shut down for extended periods to lengthen its life (10). The Belgium reactor is scheduled to stay online, until at least 2016, but would be insufficient if it were the lone reactor in operation when other reactors go off-line for repairs or if plans fall through for replacement reactors. The South African reactor is scheduled to run until 2030 but is not able to address a global supply (10).

Although there are several potential projects under way to maintain the supply of ${ }^{99} \mathrm{Mo}$, funding, transport issues, and unrealistic operational starting dates are difficult prob- lems to solve (10). In the United States, many pressing issues compete with the production of medical isotopes for scarce funding. Polls conducted in March 2010, before the disastrous consequences of the 2010 British Petroleum oil spill, revealed increased public support for nuclear energy (15); the 2010 oil spill is likely to spur additional public support for the commissioning of new nuclear reactors in the United States; however, no new reactors have been commissioned for several decades, and new plans would take several years to complete (3). Despite renewed public support for nuclear energy, there is still ongoing controversy regarding the production of highly enriched uranium and its potential for misuse for nuclear terrorism (2).

Ultimately, medical radioisotopes that cannot be stockpiled, because of their brief half-lives, are threatening to become a scarce resource. The situation is most comparable to the scarcity of solid organs for transplantation, which also have significant time constraints for medical use. Unlike other medical resources that could be stockpiled, such as vaccines or antibiotics, decisions regarding the allocation of scarce medical radioisotopes ought not to be made by individual practitioners. Rather, allocation decisions should be made by specific committees in nuclear medicine departments, acting as public guardians of this scarce resource, and establishing ethically sound guidelines and transparent criteria for priority setting.

\section{HISTORICAL LESSONS OF RATIONING AND THE "GOD COMMITTEE"}

Priority setting for scarce medical resources is nothing new; however, the frameworks for priority setting have evolved from the subjective and normative criteria used in other pioneering efforts in resource allocation. One of the most notorious cases of rationing took place after the discovery of insulin in 1921. This discovery led to a public demand for insulin in 1922 greatly exceeding the limited supply. Rationing decisions made by Dr. Frederick Banting, codiscoverer of insulin, were inappropriately based on subjective criteria, such as direct emotional appeals or political influence $(16,17)$.

In 1943, the release of penicillin for civilian use led to U.S. government rationing based on severity of infection. Although the criteria for rationing in this case were based on sound ethical frameworks, the process for establishing criteria and selecting candidates for the drug was not explained to the public or made transparent. As a result, the rationing process was severely criticized (16).

The most important and relevant lessons in priority setting can be traced to the work of what became known as the God Committee $(16,18)$, which some authors have considered to be the birth of bioethics (18). The God Committee was the first dialysis committee to form in 1961, directly consequent to the 1960 invention of the arteriovenous shunt (hemodialysis) by Belding Scribner et al. at the University of Washington $(16,18,19)$. As a result of this new therapy's limited availability, Seattle's Artificial Kidney 
Center was faced with making difficult allocation decisions. In 1961, the first 9-member priority-setting committee formed, comprising 7 lay members and 2 physicians. Medical sociologists described this committee's work in the book The Courage to Fail (20). The God Committee, or "God Squad," decisions were exposed to the public in a popular magazine article (21), leading to fundamental changes in rationing medical resources. The criteria used by the God Committee were based on utilitarian and social "worth," as determined by an all-Caucasian membership, devoid of religious, cultural, or racial diversity, which used parochial criteria to determine the net social worth of dialysis candidates. For example, children were excluded, whereas male heads of households with the largest number of dependents were given priority. Priority was also given to Washington state residents because the dialysis program was funded by state taxes. Priority was also given to the person with the largest number of dependents requiring state financial assistance, if the patient could not work. Marital status, occupation, income, education, emotional stability, and future earning potential, as well as sex, were all taken into consideration. The work of this committee, and the public criticism over its normative criteria and priority-setting methodology, eventually led Congress to approve funding for universal access to dialysis in 1972 through Medicare, with the bill taking effect on July 1, 1973 (22).

Before 1998, liver transplants were based on a first-come, first-served, process (waiting lists), and a candidate's score on the Child-Turcotte-Pugh system, a medical predictor of survivability. This scoring system was first published in 1964 (23) and is still used to assess the prognosis of chronic liver disease. Originally used to predict mortality during surgery, it is now used to decide who could most benefit by liver transplantation (16).

However, basing liver transplant prioritization solely on the Child-Turcotte-Pugh system produced a conflict between the principle of fairness and the problem of urgency. This system was criticized because it discriminated against people with less access to health care. Those with less access tend to be lower on waiting lists because it takes them longer to get on a waiting list. Attempting to predict who would most benefit from the transplant led to unintended discrimination. Liver transplants are now allocated on the basis of urgency (16). Recently, defects in this system were revealed by the liver transplant case involving Steve Jobs, CEO of Apple, Inc. In this case, bioethicists noted that his wealth created greater opportunities for him to list himself in several transplant centers as the most urgent case (24).

\section{ETHICAL FRAMEWORKS FOR ALLOCATION OF SCARCE RESOURCES}

Of the 4 core ethical principles most commonly cited in bioethics-autonomy, beneficence, nonmaleficence, and justice (25)—decisions regarding the allocation of scarce resources ought to be based on the principle of beneficence, obligating health-care providers to maximize benefits and minimize harm. This principle addresses the "Who can most benefit?" question on the basis of objective clinical parameters, but it may also take psychosocial criteria into consideration. In an organ transplant decision, negative health behaviors, such as smoking, substance abuse, other self-harm behaviors, comorbidities, and the ability to be compliant on posttransplant regimens and medications, may influence the answer to that question. Although the principle of justice is concerned with equitable access to scarce resources, ultimately the principle of beneficence may serve as an "honest broker." Autonomy, which involves patients' rights to self-determination, is not the operative principle in priority setting. However, patients may be instrumental in providing information about their preferences and health behaviors that can help determine how much they could benefit from a scarce resource. Autonomy may also be a factor in appealing a contrary decision.

\section{PRIORITY SETTING IN NUCLEAR MEDICINE: WHICH PATIENTS SHOULD BE PRIORITIZED?}

In the nuclear medicine setting, there are many patients who can reasonably, or equally, benefit from alternative diagnostic tests or treatments. Such patients should not be prioritized for scarce radioisotopes and should not be offered treatments or scans that depend on scarce radioisotopes. For example, approximately $60 \%$ of studies that rely on ${ }^{99 \mathrm{~m}} \mathrm{Tc}$ are used in cardiac studies, which can be replaced by reasonable alternatives. For example, cardiology patients who can benefit from studies using other agents (e.g., ${ }^{201} \mathrm{Tl}$ ) should not be on a prioritization list for ${ }^{99 \mathrm{~m}} \mathrm{Tc}$. In thyroid disease, patients with Graves disease should also be removed from prioritization lists for ${ }^{131} \mathrm{I}$, as most of these patients can reasonably or temporarily benefit from antithyroid drugs or surgery.

Additionally, patients with extremely limited life expectancy, who cannot stand to reasonably benefit from treatment or testing with scarce radioisotopes, should also be removed from prioritization lists. Finally, patients who must be compliant in order to benefit from a test or treatment involving scarce radioisotopes should be removed from the list if they are demonstratively noncompliant. For example, patients who refuse to take important prescribed medications should not be prioritized. Prioritization lists should be reserved only for patients who cannot be cared for by alternative standards of care (e.g., metastatic thyroid cancers that respond to ${ }^{131} \mathrm{I}$ ) or for whom diagnostic testing with a scarce radioisotope is critical.

Radioisotope shortages are no longer isolated events; they are frequent and prolonged occurrences that will continue and worsen until newer facilities are commissioned and operational. Nuclear medicine departments must form prioritysetting committees when supplies are stable so that when unanticipated shortages affect patient care, priority-setting programs are already established and can immediately go into effect when shortages are announced. Priority-setting committees should be multidisciplinary, including representatives 
from subspecialties that use scarce radioisotopes, such as cardiology and endocrinology. The committee should also include a bioethicist or at least one member of the hospital/ institutional ethics committee. Committee members should be provided training at priority-setting conferences or ask for priority-setting experts to provide on-site training. Specific criteria based on the principles of beneficence, need, and justice should be established. Income and access to health care should not factor into such decisions.

Priority-setting researchers have advocated that the priority-setting process and criteria must be transparent, helping to foster public trust (26). Criteria used by these committees should be made available in public documents that are accessible to the patient population. These could be posted on nuclear medicine department Web sites, for example. Patients need to be advised that their access to certain diagnostic tests or treatments may be limited because of a shortage of supplies. As part of a transparent process, the criteria for eligibility for scarce medical isotopes should be clearly listed, including a mechanism for patients to appeal and be reconsidered for access. Members of the priority-setting committee should also make their credentials available to the public, whereas the selection process of committee members should also be transparent. Clearly, the establishment and processes of priority-setting committees will vary depending on the institutional culture, and nuclear medicine departments will need to develop priority-setting guidelines that also take institutional culture into consideration.

\section{CONCLUSION}

When 2 nuclear reactors that were responsible for $60 \%$ of radioisotope production worldwide were shut down for safety reasons, severe problems with radioisotope production and the consequent shortages were exposed. The demand for radioisotopes is becoming greater than the supply. Until this problem is solved, ethical frameworks for priority setting must be established. Prioritization decisions should not be made by individual practitioners but by multidisciplinary priority-setting committees in nuclear medicine departments. Such committees must codify explicit criteria for the allocation of scarce radioisotopes, based on the principles of beneficence and justice. Historical lessons in resource allocation have demonstrated that criteria based on social worth or normative judgments are failed frameworks. Priority-setting criteria that are withheld from the public or patient populations affected also represent a failed process. Without appropriate priority-setting committees and transparency of their functions, exposure to the elements of chaos is imminent. In the absence of proper policies or criteria, nuclear medicine departments could be assailed by legal and ethical challenges resulting from inappropriate allocation decisions.

\section{REFERENCES}

1. Knight N. Return of the radionuclide shortage. J Nucl Med. 2009;50(7):13N$14 \mathrm{~N}$.

2. Steinbrook R. Drug shortages and public health. N Engl J Med. 2009;361:15251527.

3. IAEA addresses global radioisotope shortage. J Nucl Med. 2009;50(1):15N.

4. Committee on Medical Isotope Production Without Highly Enriched Uranium, Nuclear and Radiation Studies Board, Division of Earth and Life Studies, National Research Council of the National Academies. Medical Isotope Production Without Highly Enriched Uranium. Washington, D.C.: National Academies Press; 2009:VII-6.

5. Stafford N. Isotope shortage is limiting nuclear medicine across Europe. BMJ. 2008; 337:a1575.

6. Gould P. Medical isotope shortage reaches crisis level. Nature. 2009;460:312313.

7. Brice J. European hospitals cope with Mo-99 supply crisis. Diagnostic Imaging. 2008; 30(12). Available at: http://www.searchmedica.com/resource. html?rurl=http $\% 3 \mathrm{~A} \% 2 \mathrm{~F} \% 2 \mathrm{Fwww}$.diagnosticimaging.com $\% 2$ Fdisplay $\% 2$ Farticle $\% 2$ $\mathrm{F} 113619 \% 2 \mathrm{~F} 1354118 \& \mathrm{q}=$ European + hospitals + cope + with + Mo\&c $=$ ra\&ss $=$ diagnosticImagingLink $\& \mathrm{p}=$ Convera $\& \mathrm{fr}=$ true $\& \mathrm{ds}=0 \&$ srid $=1$. Accessed August 6, 2010.

8. Zakzouk M. The Medical Isotope Shortage: Cause, Effects and Options. Ottawa, Ontario, Canada: Industry, Infrastructure and Resources Division, Canada Library of Parliament; 2009:1-15. PRB 09-04E.

9. Sudden radioisotope shortage threatens patient care. J Nucl Med. 2008;49 (1): $17 \mathrm{~N}-18 \mathrm{~N}$.

10. The medical isotope crisis (High Scientific Council Position Paper). European Nuclear Society Web site. Available at: http://www.euronuclear.org/e-news/pdf/ e-news-26.pdf\#xml=http://euronuclear.org.master.com/texis/master/search/mysite. txt? $=$ position + paper\&order $=r \& i d=b 8482 a a 970 b 5686 \mathrm{~b} \& \mathrm{cmd}=x m l$. Accessed August 6, 2010.

11. Restarting safely: reassuring Canadians. Atomic Energy of Canada Limited (AECL) Web site. Available at: http://www.nrucanada.ca/en/home/default.aspx. Accessed August 6, 2010.

12. Canadian Nuclear Safety Commission Web site. Available at: http://www.nuclearsafety.gc.ca/eng/. Accessed July 7, 2010.

13. MAPLE reactors not a quick fix to the global isotope issue. Atomic Energy of Canada Limited (AECL) Web site. Available at: http://www.aecl.ca/NewsRoom/ News/Press-2009/090730-2.htm. Accessed August 6, 2010.

14. JRC History, 1957-1969. Joint Research Centre, European Commission, Web site. Available at: http://ec.europa.eu/dgs/jrc/index.cfm?id=3800. Accessed August 6, 2010.

15. Morgan D. Public support for nuclear power at new peak. Reuters Web site. Available at: http://www.reuters.com/article/idUSTRE62L30120100322. Accessed August 6, 2010.

16. McGough LJ, Reynolds SJ, Quinn TC, Zenilman JM. Which patients first? Setting priorities for antiretroviral therapy where resources are limited. Am J Public Health. 2005;95:1173-1180.

17. Bliss M. The Discovery of Insulin. 25th Anniversary Edition. Chicago, IL: University of Chicago Press; 2007.

18. Jonsen AR. The God squad and the origins of transplantation ethics and policy. J Law Med Ethics. 2007;35:238-240.

19. Quinton W, Dillard D, Scribner BH. Cannulation of blood vessels for prolonged hemodialysis. Trans Am Soc Artif Intern Organs. 1960;6:104-113.

20. Fox R, Swazey J. The Courage to Fail. Chicago, IL: University of Chicago Press; 1974.

21. Alexander S. They decide who lives, who dies. Life. 1962;53:102-125.

22. Publ. L. No. 92-603, 86 Stat. 1329

23. Child CG, Turcotte JG. Surgery and portal hypertension. In: Child CG, ed. The Liver and Portal Hypertension. Philadelphia, PA: Saunders; 1964:50-64.

24. Caplan A. Did Steve Jobs' wallet help cut transplant wait? MSNBC Web site. Available at: http://www.msnbc.msn.com/id/31509368. Accessed August 6, 2010 .

25. Beaumont TL, Childress JF. Principles of Biomedical Ethics. 4th ed. New York, NY: Oxford University Press; 1994.

26. Martin DK, Giacomini M, Singer PA. Fairness, accountability for reasonableness, and the views of priority setting decision-makers. Health Policy. 2002;61:279290. 